\title{
A REIFICAÇÃO DA CULTURA: UMA ANÁLISE DO PROGRAMA DE EDUCAÇÃO PA- TRIMONIAL DO TREM DA VALE SOB A ÓTICA DA INDÚSTRIA CULTURAL
}

\author{
Ingrid Anastácia de Sousa* \\ Carolina Machado Saraiva de Albuquerque Maranhão** \\ Rosany Cecilia de Sena**
}

\begin{abstract}
Resumo: A mineradora Vale S.A., ativamente atuante na região de Mariana e Ouro Preto, no Estado de Minas Gerais, idealizou um projeto direcionado à Educação Patrimonial que durante 8 anos foi considerado como um dos principais projetos com viés cultural da regiáo. Neste contexto, considerando que a Educação Patrimonial é de extrema importância para a formação da identidade cultural e social do indivíduo autônomo, objetiva-se analisar, sob a perspectiva crítica, as inter-relações entre o Programa de Educação Patrimonial Trem da Vale com o conceito que carrega a Indústria Cultural, conforme cunhado pelos teóricos críticos Theodor Adorno e Horkheimer no livro "Dialética do Esclarecimento" (1985). Para tanto, para a realização da análise empírica utilizou-se como categoria de sentido a tese de Francisco Rüdiger (2004) sobre os esquematismos interpretativos comumente presentes nas práticas da Indústria Cultural.
\end{abstract}

Palavras-chave: Indústria Cultural; Educação Patrimonial; Esquematismo; Trem da Vale.

Resumen: La minería Vale S.A., activamente actuante en la región de Mariana y Ouro Preto, en el Estado de Minas Gerais, ideó un proyecto dirigido a la Educación Patrimonial que durante 8 años fue considerado como uno de los principales proyectos con sesgo cultural de la región. En este contexto, considerando que la Educación Patrimonial es de extrema importancia para la formación de la identidad cultural y social del individuo autónomo, se pretende analizar, desde la perspectiva crítica, las interrelaciones entre el Programa de Educación Patrimonial Tren de la Vale con el concepto que lleva la Industria Cultural, según lo acuñado por los teóricos críticos Theodor Adorno y Horkheimer en el libro "Dialéctica del Iluminismo". Para ello, para la realización del análisis empírica se utilizó como categoría de sentido la tesis de Francisco Rüdiger sobre los esquemas interpretativos comúnmente presentes en las prácticas de la Industria Cultural.

Palabras claves: Industria Cultural; Educación Patrimonial; esquematismo; Tren de la Vale.

\section{Introdução}

As cidades de Mariana e Ouro Preto, localizadas ao longo da Estrada Real, no

\footnotetext{
* Bacharel em administração pela Universidade Federal de Ouro Preto - UFOP

** Doutora em administração e Profa. Adjunta na Universidade Federal de Ouro Preto - UFOP

*** Bacharelanda em administração pela Universidade Federal de Ouro Preto - UFOP
}

Estado de Minas Gerais, carregam em sua arquitetura e tradições imateriais, inestimável valor para o Patrimônio Cultural brasileiro - e mundial. Neste contexto, a mineradora Vale S.A., inserida e ativamente atuante na região, tanto na perspectiva econômica quanto na ambiental, idealizou o Programa de Educação Patrimonial Trem da Vale, que foi um dos principais projetos culturais da região.

SOUSA, Ingrid Anastácia de; MARANHÃO, Carolina Machado Saraiva de Albuquerque; SENA, Rosany Cecília de. A Reificação da Cultura: Uma Análise do Programa de Educação Patrimonial do Trem da Vale sob a ótica da Indústria Cultural. Revista Sul-Americana de Filosofia e Educação. Número 29: nov./2017-abr./ 2018, p. 71-84. DOI: https://doi.org/10.26512/resafe.v0i29.21007 
De acordo com Florêncio et al. (2014) a Educação Patrimonial é constituída por todos os processos educativos formais - $e$ não formais - que detém o patrimônio cultural como ator principal. E os processos educativos desta educação patrimonial devem buscar a construção coletiva e democrática do conhecimento, através do diálogo permanente entre os agentes culturais e sociais e pela participação efetiva das comunidades detentoras e produtoras das referências culturais, nas quais coexistem diversas noções de Patrimônio Cultural.

Considerando que a Educação Patrimonial é de extrema importância para a formação da identidade cultural e social do indivíduo autônomo, objetiva-se analisar, sob a perspectiva da Teoria Crítica, a existência de traços da Indústria Cultural no Programa de Educação Patrimonial Trem da Vale, conforme o conceito de Indústria Cultural cunhado pelos teóricos críticos Theodor Adorno e Horkheimer no livro "Dialética do Esclarecimento".

Para tanto, utiliza-se da tese de Francisco Rüdiger (2004) sobre os esquematismos interpretativos comumente presentes nas práticas da Indústria Cultural, como orientação para a análise empírica dos dados, coletados através da análise fílmica do "Documentário Projeto Trem da Vale" e da análise do discurso como método de investigação, tendo como referência o livro " $\mathrm{Ou}$ tras memórias, outros patrimônios: relato técnico do Programa de Educação Patrimonial Trem da Vale".

Os esquematismos propostos, utilizados para direcionar as análises preliminares deste estudo, são de relevante importância, contudo, não se busca aqui reduzir ou positivar a análise crítica da Indústria Cultural aos esquemas propostos, mas sim, evidenciar como os pressupostos da Indústria Cultural podem ser identificados em outros ramos culturais, que vão além das telenovelas e rádios, transformando o que antes era considerado cultura em um mero objeto mercadológico.

\section{Programa de Educação Patrimonial Trem da Vale}

O Trem da Vale, inaugurado em maio de 2006 por meio da Lei Rouanet $n^{\circ}$ 8.313/91, Lei Federal de Incentivo à Cultura do Ministério da Cultura, foi um projeto financiado e realizado pela Fundação Vale instituição do grupo da mineradora Vale S.A.- juntamente ao Santa Rosa Bureau Cultural, parceiro executor do programa, entre outros parceiros institucionais como a Universidade Federal de Ouro Preto e a Ferrovia Centro-Atlântica. Em 2008, o projeto passou a ser denominado Programa de Educação Patrimonial Trem da Vale devido à estrutura e abrangência das ações na região (Fundação Vale, 2010).

Este projeto foi responsável pela recuperação de 18 quilômetros de linha férrea $e$ de quatro estações existentes entre as cidades de Mariana e Ouro Preto, sendo apresentado pelos seus idealizadores como o maior projeto de Educação Patrimonial do Brasil e como forte atrativo turístico para a região. Inicialmente era composto por três subprogramas, a saber (Fundação Vale, 2010):

- Vale Conhecer: compreendia ações pontuais nas escolas de ensino fundamental de Mariana e Ouro Preto com professores $e$ alunos junto a funcionários do programa a fim de promover noções básicas do patrimônio cultural destas cidades. Englobava também a formação de professores $e$ ações com estudantes a partir da préadolescência em atividades nos espaços do trem;

- Vale Registrar: tratava-se da realização de registros audiovisuais, da produção e capacitação nas áreas de 
vídeo e atuação sobre a história oral dos moradores, a fim de criar um acervo histórico da região, sobre algum tema específico como mineração e ferrovia;

- Vale Promover: com cunho turístico, desenvolvia atividades nas estações voltadas para os turistas que faziam o passeio de trem ou que pretendiam conhecer os espaços, objetos $e$ informações históricas ali expostas.

\section{Educação Patrimonial}

De acordo com Maltêz et al. (2010) a origem da expressão Educação Patrimonial é inglesa - Heritage Education. No Brasil, a perspectiva de Educação Patrimonial surgiu a partir do evento ocorrido no Museu Imperial em Petrópolis, no estado do Rio de Janeiro, em 1983 no "I Seminário de Uso Educacional de Museus e Monumentos" (Grunberg, 2000, p.168).

Segundo Florêncio et al. (2014) podese entender Educação Patrimonial da seguinte forma:

(...) Educação Patrimonial constituise de todos os processos educativos formais e não formais que têm como foco o Patrimônio Cultural, apropriado socialmente como recurso para a compreensão sóciohistórica das referências culturais em todas as suas manifestações, a fim de colaborar para seu reconhecimento, sua valorização e preservação. Considera ainda que os processos educativos devem primar pela construção coletiva e democrática do conhecimento, por meio do diálogo permanente entre os agentes culturais e sociais e pela participação efetiva das comunidades detentoras e produtoras das referên- cias culturais, onde convivem diversas noções de Patrimônio Cultural (Florêncio et al., 2014, p.19).

Neste sentido, a Educação Patrimonial utiliza os bens culturais como base para o desenvolvimento de um estudo pedagógico, isto é, o Patrimônio Cultural se torna um instrumento importante para o processo de ensino e desenvolvimento da conscientização patrimonial (Grunberg, 2000).

César et al. (2011) afirmam que as sociedades procuram deixar legados para as gerações futuras e que o Patrimônio Cultural é uma construção social que busca preservar a essência da comunidade que o constituiu. A Educação Patrimonial contribui para a recuperação e valorização dessa cultura local quando promove a educação da população sobre sua própria identidade cultural, sendo importante para uma espécie de alfabetização cultural, levando o indivíduo a pensar e/ou repensar o meio em que vive, buscando entender o passado e o presente.

César et al. (2011) afirmam que o patrimônio cultural é o legado de uma sociedade, que ultrapassa o tempo e atesta para as gerações posteriores a sua própria origem. Este patrimônio está ligado ao legado memorial da comunidade, estabelecendo um vínculo efetivo com o passado, permitindo que o indivíduo pense criticamente sobre o presente e o futuro da comunidade.

Para Maltêz et al. (2010) atualmente o Patrimônio Cultural vai além de construções de reconhecido valor histórico, incluindo-se neste cenário manifestações culturais corriqueiras, pratos típicos, danças e costumes em geral. Abre-se caminho também para a questão da preservação ambiental, na concepção "do meio ambiente como um bem cultural a ser preservado." (Costa, 2011, p.46).

A Educação Patrimonial contribui para a formação de uma identidade cultural - 
crítica - por parte do indivíduo, uma vez que, segundo Maltêz et al., (2010) o processo de conhecimento do bem cultural e, consequentemente, da Educação Patrimonial, envolve a participação dos sentidos e o sentimento de reconhecimento diante do bem.

Neste sentido, a Educação Patrimonial contribui para a formação de cidadãos críticos, conscientes da pluralidade cultural do meio em que vivem, buscando despertar a conscientização do indivíduo, enquanto sujeito, acerca de seus deveres de preservação, promoção, valorização e construção do Patrimônio Cultural em todas as suas vertentes (Maltêz et al., 2010).

\section{Esquematismo de Rüdiger e a Indústria Cul- tural}

Conforme elucidado por Rüdiger (2004), o termo Indústria Cultural, cunhado pelos teóricos críticos Adorno e Horkheimer em dissonância ao conceito ideológico de cultura de massa, não se trata do conjunto de empresas produtoras ou das formas de difusão dos bens culturais, mas sim do processo histórico de transformação da mercadoria em um determinante da vida social, $e$ por consequência, da cultura em mercadoria, ou seja, mais vale seu valor de tro$\mathrm{ca} /$ consumo do que seu valor de uso. $\mathrm{O}$ foco está no processo social e não exclusivamente no produto em si.

O esvaziamento crítico da cultura produz indivíduos felizes, já que estão adequados ao sistema. Essa previsibilidade gera para o indivíduo uma espécie de serenidade, pois usurpa dele a responsabilidade de interpretar as coisas, de ter que estar atento à sua vida concreta: "a Indústria Cultural executa o esquematismo como primeiro serviço a seus clientes (...). Para os consumidores nada há mais para classificar que não tenha sido antecipado no esquematismo da produção" (Adorno e Horkheimer, 1985 , p. 145 . Grifo nosso).
Isso é chamado de "reprodução simples do espírito" em que há uma espécie de catarse da necessidade de transcendência do indivíduo, sem que isso signifique esforço e comprometimento "sem que ocorra qualquer amadurecimento, qualquer crescimento espiritual" (Duarte, 2003, p. 56).

Deturpados pela indústria cultural, os esquemas vêm a constituir uma espécie de estrutura articuladora do fetichismo de mercadoria, com um poder guardado dentro de si que é de satisfazer integralmente todas as nossas necessidades (Rüdiger, 2004). A utilização de esquemas impostos às mercadorias culturais pela indústria facilita a vida $e$ agiliza o processo de compreensão dos fenômenos, pois "entrega ao seu aparato perceptivo uma realidade repleta de respostas prontas" (Silva, 2013) em que os esforços de reflexão não são mais necessários, uma vez que se aprende a pensar o mundo de uma maneira pré-determinada, ao aceitar que só existe uma única interpretação padronizada para cada coisa.

Neste sentido, o autor destaca os principais esquemas abordados por Adorno que podem ser comumente encontrados nas práticas da indústria cultural, a conhecer: padronização; pseudo-individuação; glamourização; hibridização; esportização; aproximação; personalização e estereotipagem (Rüdiger, 2004).

A padronização refere-se às formas $e$ estruturas dos produtos que apresentam as mesmas características de outros do mesmo gênero, ao mesmo tempo em que devem apresentar especificidades que os diferencie e torne possível sua comercialização, caracterizando a ocorrência do esquema de pseudo-individuação.

A glamourização busca embutir aspectos promocionais que engrandecem até as mais simples características das mercadorias, como forma de desviar a atenção do sujeito da verdadeira essência ou intenção imersa nos bens culturais. 
A hibridização refere-se ao agrupamento de gêneros associados ao produto cultural, que nos apresenta uma variedade de formas e/ou visões na qual determinado fenômeno pode ser apresentado buscando representar superficialmente uma variedade de consumidores.

No esquema de esportização as mercadorias passam as ser esquematizadas com base em "roteiros", que definem todo um processo de estruturação $e$ interpretação a ser seguido. $\mathrm{O}$ esquematismo de aproximação, através do consumo, atribui aspectos as mercadorias que fazem com que o sujeito sinta-se parte integrante de sua essência, tornando possível acessá-la de forma imediata e da maneira que desejar, apropriandose desta como uma representação social $e$ pessoal.

Já o esquema de personalização- que se entende como uma des-historização- refere-se à associação dos fatos a pessoas, isoladamente, desconsiderando todo o processo ideológico, político e cultural que culminou em sua ocorrência. O último esquema a estereotipagem, consiste em meios de apresentar o material cultural reduzindo sua complexidade e simplificando a compreensão dos seus significados.

O objetivo do Rüdiger (2004) ao sintetizar estas categorias não é reduzir a indústria cultural a oito fenômenos, aliás, isto seria papel da própria indústria cultural. Sua proposta foi organizar as práticas mais comuns da indústria cultural no que chamamos de categorias de sentido - categorias como organização de ideias, que não se restringem a elas, mas a ultrapassam e, em grupo, constroem uma constelação de ideias. Vale ressaltar, que não são categorias positivas, ou seja, que se esgotam na complexidade do tema, mas categorias que normalmente são encontradas nos bens oriundos da Indústria Cultural, ressaltando que "não se pretende afirmar que ele seja o único ou que as mercadorias culturais sejam meramente agenciamentos de esquematismos" (Rüdiger, 2004, p. 196).

\section{Metodologia}

Esta pesquisa, de caráter descritiva analítica, para análise empírica dos dados teve como corpus o "Documentário Projeto Trem da Vale" e o livro "Outras memórias, outros patrimônios: relato técnico do Programa de Educação Patrimonial Trem da Vale".

Para a análise fílmica, optou-se pela técnica de decupagem. O documentário foi divido em 12 sequências, buscando agrupar os eventos de forma lógica permitindo uma análise de interligação entre as diferentes sequências e os possíveis esquematismos correspondentes.

Considerando os objetivos do estudo $e$, tendo como referência de dados o livro "Outras memórias, outros patrimônios: relato técnico do Programa de Educação Patrimonial Trem da Vale", optou-se por realizar uma análise preliminar dos depoimentos dos coordenadores técnicos responsáveis pela implantação e/ou gestão do programa entre os anos de 2003 e 2010 presentes em uma seção do livro, compreendida entre as páginas 216 e 357.

\section{Análise dos dados}

Para o desenvolvimento da análise do filme, os dados foram agrupados de forma descritiva conforme a tabela 1, na qual foi realizada a decupagem do documentário e, em seguida, uma análise mais aprofundada da real proposta do filme, a fim de considerar as mensagens e aspectos sociais, culturais e políticos nos quais se podem identificar alusões aos esquematismos propostos por Rüdiger (2004) que norteiam a prática da Indústria Cultural, que neste caso é utili- 
zado tanto como base teórica quanto metodológica.

Tabela 1- Decupagem das sequências temáticas

\begin{tabular}{|c|c|c|c|}
\hline $\begin{array}{l}\text { Sequência } \\
\text { temática }\end{array}$ & Inicio & Final & Descrição da sequên cia \\
\hline 1 & $00,000^{\prime} 00$ & $0001=20$ & $\begin{array}{l}\text { A abertura do filme é dividida em três temas centrai s, que podem } \\
\text { ser identificados por estarem desta cados por meio de titulos de } \\
\text { efeito para realizar a transição de um tema para outro, a saber: } \\
\text { trilhar a história com a arte; trilhar a emoção do passado com o } \\
\text { presente e trilhar os rumos do desenvol vimento. A trilha sonora é } \\
\text { de sons instrumentais repetitivos com sons de sinos ao fundo que } \\
\text { gera ao telespectador uma sensação de transe, de hipnose. } \\
\text { O primeiro tema intitulado "Trilhar a História com a arte" é } \\
\text { ini ciado com as falas do Padre Simões, então pároco da paróquia } \\
\text { do Pilar em Ouro Preto, fal ando da esperança e da certeza do } \\
\text { retorno da Maria-Fumaça. O segundo tema "Trilhar a emoção do } \\
\text { passado com o presente" apresenta a moradora e professora de } \\
\text { Mariana, a Sra Hebe Rola falando sobre a emoção que sente } \\
\text { sobre o retorno do trem. Enfim, "Trilhar os rumos do } \\
\text { desenvolvimento" traz a visão do então presidente da Vale, Roger } \\
\text { Agnelli, sobre ter a oportunidade de poder ver renascer o trem } \\
\text { de levar a importância do que é uma ferrovia para o restante do } \\
\text { pais. }\end{array}$ \\
\hline 2 & $00^{\prime} 01^{\prime \prime} 22$ & $0001=53$ & $\begin{array}{l}\text { Menciona-se em um titulo destacando a cidade de Mariana como } \\
\text { primeira capital de Minas Gerais e, em seguida, a cidade de Ouro } \\
\text { Preto como patrimônio cultural da humanidade. Logo após, tem- } \\
\text { se a fala da Sra. Olinta Cardoso, Diretora Superintendente da } \\
\text { Fundação Vale do Rio Doce, que diz que durante a viagem de } \\
\text { Mariana a Ouro Preto pode perceber a reação e a vibração das } \\
\text { comuni dades, o que superou todas as suas expectativas em } \\
\text { relação à volta do trem. } \\
\text { A cena se inicia com uma música in strumental mais rápida que } \\
\text { remete ao som de berimbau e tambores ao fundo. Em uma bela } \\
\text { imagem do trem circulando no trecho já restaurado, destaca-se a } \\
\text { seguinte frase junto a logo da mineradora "Trem da Vale: Um } \\
\text { dos mai ores projetos de Educação Patrimonial do Brasil". }\end{array}$ \\
\hline 4 & $000^{\prime \prime} 05$ & $0003=19$ & $\begin{array}{l}\text { Evidencia-se a primeira visita realizada em } 2003 \text {, no trecho } \\
\text { ferroviário a ser restaurado, pela equipe responsável pel o proj eto. } \\
\text { As sequências seguintes são apresentadas de maneira curta } \\
\text { rápida, como se fossem cronometradas, relatando as obras } \\
\text { realizadas no periodo de agosto de } 2005 \text { a maio de } 2006 \text { na } \\
\text { estação de Mariana. Em paralelo a estas cenas do antes e depois } \\
\text { das estações destacam-se, em forma textual, alguns numeros } \\
\text { representativos para o projeto, como o investimento de } 48,5 \\
\text { milhöes de reais; } 800 \text { empregos gerados; } 200 \text { trabalhadores } \\
\text { responsáveis pelarestauração devagóes; } 3.500 \text { toneladas de brita. }\end{array}$ \\
\hline
\end{tabular}




\begin{tabular}{|c|c|c|}
\hline 5 & $00^{\prime} 03^{\prime \prime 2} 200^{\prime} 03{ }^{\prime \prime} 36$ & $\begin{array}{l}\text { No mesmo estlo da sequencia anterior, e relatada a recuperaçá } \\
\text { da Estação de Passagem de Mariana, distrito de Mariana. } \\
\text { Sequências curtas e rảpidas mostrando as pessoas que estavam } \\
\text { trabalhando na obra e o antes e o depois da estação. Novamente, } \\
\text { junto às cenas, aparecem tex tos com dados sobre o projeto, a } \\
\text { saber: realizadas } 48 \text { obras de contenção; } 490 \text { empregados nas } \\
\text { obras de recuperação; } 31.500 \text { domentes utilizados. }\end{array}$ \\
\hline 6 & $00^{\prime} 03^{\prime \prime} 37 \quad 00^{\prime} 03^{\prime \prime} 56$ & $\begin{array}{l}\text { Outro depoimento do Padre Simões mencionando a importância } \\
\text { das estaços para a economia local, pois segundo o mesmo } \\
\text { "Muita gente ganhava dinheiro a custa da estação". }\end{array}$ \\
\hline 7 & $00^{\prime} 04^{\prime \prime} 19 \quad 0005^{\prime \prime 2}$ & $\begin{array}{l}\text { Ainda sob uma trilha sonora instrumental mais rápida e repe titiva, } \\
\text { apresentam-se as obras realizadas de agosto de } 2005 \text { a maio de } \\
2006 \text { com o mesmo padrão de sequências rápidas, quase que } \\
\text { cronometradas, imagens dos trabalhadores e cenas do antes e do } \\
\text { depois das Estações de Vitorino Diase de Ouro Preto. }\end{array}$ \\
\hline 8 & $00^{\prime} 05^{\prime \prime} 21 \quad 00^{\prime} 05^{\prime \prime 2} 27$ & $\begin{array}{l}\text { Um homem com duas crianças pequenas, a parentemente seus } \\
\text { filhos, todos sem identificação, diz que aquele é um momento } \\
\text { maravilhoso em poder dar um depoimento, para engrandecer o } \\
\text { projeto, que segundo ele é maravilhoso. }\end{array}$ \\
\hline 9 & $00^{\prime} 05^{\prime \prime} 28 \quad 0005^{\prime \prime} 55$ & $\begin{array}{l}\text { Cenas da inauguração do trem da Vale, em maio de } 2006 \text {, com a } \\
\text { presença de representantes politicos da época como o ex - } \\
\text { presidente Luis Inácio Lula da Silva com sua esposa Marisa Silva, } \\
\text { o então governador do Estado de Minas Gerais, Aécio Neves, os } \\
\text { antigos prefeitos das cidades de Mariana e Ouro Preto, o Ex- } \\
\text { presidente da Vale S.A. Roger Agnelli, e Dom Luciano Mendes } \\
\text { de Almeida, representando a estância religiosa da região, } \\
\text { enquanto Arcebispo da Arquidiocese de Mhriana. }\end{array}$ \\
\hline 10 & $0005^{\prime \prime} 56 \quad 00077^{\prime \prime} 01$ & $\begin{array}{l}\text { Cenas da Estação de Mariana já restaurada, com apresentação dos } \\
\text { espaços do proj eto: Praça lúdico musical; vagão oficina de } \\
\text { história; vagão café; vagão dos sentidos; biblioteca e sala } \\
\text { multiuso. Todos os espaços são mostrados com muitas crianças e } \\
\text { adultos na estação usufruindo e brincando. }\end{array}$ \\
\hline 11 & $00^{\prime} 07^{\prime \prime} 02 \quad 00^{\prime} 07^{\prime \prime} 12$ & $\begin{array}{l}\text { Uma senhora, não identificada, agradece a mineradora Vale por } \\
\text { proporcionar a ela a oportunidade de realizar o passeio de trem na } \\
\text { cidade onde o marido da mesma nasceu. }\end{array}$ \\
\hline 12 & $00^{\prime} 07^{\prime \prime} 16 \quad 00^{\prime} 10^{\prime \prime} 14$ & $\begin{array}{l}\text { Apresentação do Programa de Educação Patrimonial dando } \\
\text { ênfase ao atendimento de } 11.000 \text { adolescentes e crianças por ano. } \\
\text { Sequências das atividades desenvolvidas com crianças na cidade } \\
\text { de Ouro Preto, no Circo da Estação; as atividades realizadas pelo } \\
\text { vale conhecer que consiste em um circuito integrado de ensino; as } \\
\text { ações de educação continuada no circo; as oficinas de educação } \\
\text { ambiental. Apresentam-se os quiosques multimidias, as salas } \\
\text { expositivas; salas de histórias; espaço UFOP, vagão sonoro- } \\
\text { ambiental; oficinas de educação patrimonial entre outros projetos } \\
\text { desenvolvidos. }\end{array}$ \\
\hline
\end{tabular}

Fonte: Elaborado pelos autores (2016).

Após a organização e descrição das sequências temáticas, ao se analisar a ideia geral do documentário, tem-se a percepção da utilização do esquema de estereotipagem na construção do mesmo, considerando que este apresenta um projeto que reduz a complexidade inerente a um programa de Educação Patrimonial, uma vez que são criados meios de facilitar a assimilação $e$ interpretação da História ferroviária e de sua relação com o desenvolvimento local, considerando apenas as visões de um pequeno grupo de pessoas, desconsiderando a complexidade cultural das comunidades.

Outro esquema presente no documentário em geral, foi à personalização. Originalmente, o trem era um meio de transporte de passageiros de Miguel Burnier, distrito de Ouro Preto, com destino a cidade de Ponte Nova, porém o projeto se propôs a restaurar apenas 18 quilômetros do trecho ferroviário entre Ouro Preto e Mariana, cidades 
onde a mineradora Vale S.A. gera maior impacto tanto econômico quanto ambiental.

Nota-se também a presença recorrente do esquematismo de aproximação em sequências consideradas romantizadas, que apelam para os sentimentos de identidade local. Utiliza-se de imagens que fazem referências à cultura e à história da região, como por exemplo, a utilização, no decorrer de todo o documentário, de imagens de trilhos e imagens católicas entre a mudança de uma sequência para a outra. Busca-se, assim, aproximar o Projeto dos anseios e da realidade da comunidade na qual ele estava sendo implantado, sabendo-se que Mariana e Ouro Preto são cidades onde o catolicismo tem forte influência social e cultural.

Na sequência 1, as três pessoas entrevistadas são referências no campo religioso (Padre Simões), educacional (Professora Hebe Rola) e empresarial (Roger Agnelli, então presidente da Vale S.A.) da região, evidenciando a participação de pessoas influentes de setores marcantes para a localidade, uma vez que as cidades de Mariana e Ouro Preto são reconhecidas pela forte tradição católica, pela sua importância histórica e pela interdependência da mineração, maior fonte de renda da população local, principalmente em Mariana. Ou seja, utiliza-se do esquematismo de aproximação para criar no espectador a sensação de reconhecimento e de representação por parte destes "líderes".

Na sequência 2, destaca-se também o esquematismo de aproximação ao se mencionar as peculiaridades de Mariana, como primeira capital de Minas Gerais, e Ouro Preto como patrimônio cultural da humanidade. Busca-se criar um sentimento de pertencimento e de satisfação por parte da comunidade em integrar um projeto relevante que, em tese, integra culturalmente ambas as cidades. Estas mesmas características de aproximação podem ser notadas na sequência 6 , uma vez que novamente tem-se um apelo à importância histórica do trem para a economia da região feita por Padre Simões que, até hoje após sua morte, é considerado uma referência tanto religiosa como social; em sua fala lembra dos jovens que ficavam nas estações vendendo doces, pão de queijo e pipocas.

A ideia do esquematismo de pseudoindividuação está intimamente ligada à de padronização: embora seja um trem turístico como tantos outros no Brasil, o documentário o apresenta como algo único, idealizado para a comunidade, atribuindo aspectos que remetem à individualidade cultural de cada morador das cidades envolvidas no projeto, como observado na sequência 11, por exemplo, na qual a senhora entrevistada tem a percepção de que o projeto foi realizado pensando nela e em suas emoções individuais, pois relata que naquele trem ela revive as lembranças deixadas pelo marido, natural da cidade de Mariana. $\mathrm{O}$ mesmo esquematismo ocorre na sequência 8, quando é utilizada a imagem de uma família para engrandecer o projeto. Assim, em ambas as sequência, 8 e 11, objetiva-se mostrar a relevância do projeto, ao evidenciar o depoimento de moradores da localidade que relatam o seu contentamento com a volta do trem e os sentimentos que proporcionará um passeio que remete ao $\mathrm{Pa}$ trimônio Cultural (e ambiental) de sua região, criando um sentimento de pertencimento na construção da História da comunidade.

Outro esquematismo recorrente é a glamourização, no sentido em que esta é utilizada no filme para evidenciar pequenos detalhes, seja em forma textual ou em imagens, que engrandecem o projeto e desviam o foco dos espectadores da ação em si promovida, que em tese consistiria na utilização do bem cultural "trem" para a Educação Patrimonial, ou seja, se o real objetivo é a conservação da história através da Educação Patrimonial, que consiste no empode- 
ramento do sujeito, a menção dos valores gastos no projeto deveria ser irrelevante, dada a importância da proposta para a cultura não só regional, como nacional. Neste sentido, as sequências $2,3,4,5,9$ e 12 apresentam aspectos do esquema referido.

Percebe-se o esquematismo de glamourização, tanto na fala da então presidente da Fundação Vale na sequência 2, que diz que a reação da comunidade superou suas expectativas, ou seja, o impacto do projeto foi maior do que o esperado, quanto no momento em que se destaca o dia da inauguração do trem, com a presença de políticos importantes da época - como o presidente da República - representantes religiosos e conhecidos empresários, descritos na sequência 9 , ambos remetem para a importância do projeto que os organizadores querem evidenciar, mostrando apenas pessoas conhecidas e influentes socialmente, que participaram e apoiaram o desenvolvimento do projeto como sendo uma fonte não só cultural como econômica.

Já na sequência 3, utiliza-se do esquematismo de glamourização quando o projeto é mencionado como um dos maiores projetos de educação patrimonial do Brasil, magnificando os investimentos $e$ demonstrando que a organização que prove o projeto não poupou esforços para tornar real a "volta" do trem para as comunidades marianense e ouropretana. Ainda sobre a glamourização, nas sequências 4,5 e 12 explicita-se o mesmo padrão de informações, em que é dada ênfase a questões de cunho mais estrutural do projeto, através da divulgação de dados quantitativos, como os valores monetários e materiais gastos, número de empregos gerados e o número de pessoas atendidas pelo projeto; detalhes estes que enobrecem a ação $e$ a atitude da empresa patrocinadora.

Já nas sequências 4, 5, 7 e 10 tem-se o mesmo padrão de apresentação, que as caracterizam como esquematismo de espor- tização, pois apresentam uma sequência de ações realizadas pela equipe técnica e de obras, que levaram a concretização da proposta do projeto, principalmente em termos estruturais na restauração das estações. As sequências foram organizadas como se fosse apresentado o protocolo de metas $e$ ações seguidas, que garantiu a efetivação $e$ o sucesso do projeto na visão de seus idealizadores, o que remete também ao esquematismo de glamourização, pois ao destacar os esforços monetários e físicos que a Vale disponibilizou, busca-se demonstrar a preocupação da empresa em fazer deste um grande projeto cultural.

Já na análise dos depoimentos do livro, identificou-se a presença de 7 esquematismos, que implícita ou explicitamente, são elucidados nos relatos analisados, são eles: padronização; pseudo-individuação; glamourização; aproximação; personalização; hibridização e estereotipagem.

Acredita-se que, por se direcionar os depoimentos através de um roteiro de perguntas e por se tratar de relatos apenas de uma parte da equipe mais gerencial, estas experiências foram relatadas de forma (oportunamente?) similar apontando basicamente os mesmos desafios, obstáculos e conquistas culminando, de modo geral, na recorrência dos esquematismos citados anteriormente em cada discurso.

Apresenta-se abaixo no quadro 1 a identificação dos profissionais selecionados para compor a seção de depoimentos do livro. 
Quadro 1. Informações sobre os profissionais que formaram o conjunto de depoimentos analisados.

\begin{tabular}{|c|l|l|l||}
$\begin{array}{c}\text { Referência do } \\
\text { Depoimento }\end{array}$ & Responsável & \multicolumn{1}{|c||}{ Função } & \multicolumn{1}{c||}{ Profissão } \\
\hline $\begin{array}{c}1^{\circ} \\
\text { Pág. 216 a 239) }\end{array}$ & $\begin{array}{l}\text { Eleonora Santa } \\
\text { Rosa }\end{array}$ & $\begin{array}{l}\text { Idealizadora e coordenadora geral do programa e } \\
\text { fundadora da produtora cultural Santa Rosa Bureau } \\
\text { Cultural, empresa responsável pela concepção e } \\
\text { gestão do Projeto Trem da Vale. }\end{array}$ & Comunicadora Social \\
\hline $2^{\circ}$ & Jason Barroso & $\begin{array}{l}\text { Idealizador e consultor do programa que trouxe a } \\
\text { ideia de inserção do tema Educação patrimonial, e } \\
\text { supervisor do subprograma vale registrar, que } \\
\text { consiste em registros audiovisuais e oficinasda } \\
\text { história oral ligada ao patrimônio. }\end{array}$ & Arquiteto e Urbanista \\
\hline $\begin{array}{c}\text { (Pág. 270 a 291) } \\
3^{\circ}\end{array}$ & Santa Rosa & $\begin{array}{l}\text { Corresponsável pelo projeto arquitetônico e de } \\
\text { restauração da linha e das estações do trecho } \\
\text { ferroviário. }\end{array}$ & Arquiteta \\
\hline $4^{\circ}$ & $\begin{array}{l}\text { Coordenadora executiva do programa entre 2008 e e } \\
\text { 2010, responsável pela gestão do planejemento do } \\
\text { projeto }\end{array}$ & $\begin{array}{l}\text { Economista e Mestre } \\
\text { em Planejamento }\end{array}$ \\
Urbano
\end{tabular}

Fonte: Elaborado pelos autores, 2016.

Os esquemas de padronização $e$ pseudo-individuação estão intimamente ligados e presentes em todos os depoimentos, para os entrevistados o trem turístico seria apenas uma dimensão de um projeto muito maior, o de Educação Patrimonial, e é justamente este fator que o diferencia dos demais trens turísticos do Brasil. De acordo com o depoimento de Luciana Lamounier o Trem da Vale se destaca por "ter juntado ao turismo todo um programa de atividades para que a comunidade se aproprie dos 
espaços e os utilize da melhor maneira possível" (Fundação Vale, 2010, p. 351).

Nota-se que o esquematismo mais recorrente nos depoimentos é o da glamourização, no sentido de engrandecer a proposta do programa, por exemplo, em todos os depoimentos mencionam-se palavras como: inédito; inovador; único; diferente; complexo; exemplo; referência e ousadia ao se mencionar a proposta do programa como algo pioneiro no Brasil. Em seu depoimento Eleonora diz que para ela "o Trem da Vale é o único que pode ser chamado propriamente de trem turístico, histórico e cultural, voltado para a educação patrimonial" (Fundação Vale, 2010, p.219), reforçando a característica de glamourização do programa.

O desenvolvimento de um esquema de aproximação era um fator primordial para a execução e o sucesso do programa de Educação Patrimonial, pois havia uma necessidade de integrar a população de modo que esta se apropriasse deste projeto, por isso, de acordo com Juca Villaschi, sexto depoimento, foi necessário estruturar $e$ desenvolver uma "metodologia de aproximação" (Fundação Vale, 2010, p. 325) devido à resistência inicial da população.

A própria revitalização da malha ferroviária, por si só, já seria um fator de aproximação com a comunidade local, ao considerarmos a importância e a história da ferrovia na cultura mineira, na qual o trem é tido como patrimônio afetivo, conforme exposto no depoimento de Jason Barroso. Porém, acredita-se, que esta resistência da população pode estar pautada na imagem da empresa na região e pelo fato de que na concepção do projeto não houve um envolvimento da comunidade, uma vez que os primórdios do mesmo foram definidos por pessoas de outras regiões de Minas, nem mesmo os funcionários da Vale participaram deste processo.
O trecho revitalizado pelo programa em estudo, na realidade estava compreendido entre Miguel Burnier (distrito de Ouro Preto) e Ponte Nova, pelo qual se realizava transporte de passageiros e, em um segundo momento, na década de 80, o trecho Ouro Preto-Mariana foi revitalizado apenas para fins turísticos. Porém, ambas as experiências não obtiveram sucesso, por isso o projeto Trem da Vale buscou apresentar uma proposta inovadora que envolvesse tanto moradores quanto turistas destas duas cidades. A opção de trabalhar com essas cidades que sofrem grande impacto com a atividade da organização e a própria denominação "Trem da Vale" nos remete a utilização do esquema de personalização, provocando uma ruptura histórica entre a comunidade $e$ a atividade da maria-fumaça desenvolvida em sua gênese.

Em relação ao esquema de hibridização percebe-se que o Trem da Vale apresenta uma coletânea de visões sobre temas ligados ao patrimônio, visando dar maior ênfase ao programa que estava sendo desenvolvido, como forma de apresentar à comunidade uma opção efetiva para a busca de seu empoderamento cultural, através de oficinas $e$ atividades que enquadrassem os diversos públicos do projeto.

No que se refere ao esquema de estereotipagem a criação de roteiros e divisões do programa em eixos temáticos que buscam estruturá-lo de modo a facilitar a assimilação de seu conteúdo, contribuem para dar ao projeto ares de limitação, principalmente referindo-se a História local, que é delimitada para ser mais facilmente entendida e apreendida. A complexidade deste projeto de Educação Patrimonial abriu espaço para que a estereotipagem dos processos educacionais fossem realizados com certa naturalidade durante o programa.

Ao identificar a presença destes esquematismos interpretativos nestas duas análises, pode-se observar, assim, a presen- 
ça de vertentes da Indústria Cultural presentes no Projeto de Educação Patrimonial Trem da Vale. Contudo, ressalta-se que não se deve delimitar tal projeto apenas por estes esquemas, uma vez que as práticas da Indústria Cultural abrem espaço para um processo dialético contínuo.

\section{Considerações Finais}

Considerando a amplitude dos dados e a complexidade como estão apresentados, optou-se, neste estudo, por discutir como vertentes da Indústria Cultural podem nos servir de apoio para analisar o Programa de Educação Patrimonial Trem da Vale, à luz da Teoria Crítica. De fato não há problemas no investimento do setor privado, no caso da empresa Vale S.A., de recursos em programas de Educação Patrimonial, deve-se, no entanto, analisar as mensagens subliminares que podem se apresentar emaranhadas neste tipo de ação.

A partir da análise filmica e dos depoimentos do livro permitiu-se, além da associação aos esquematismos, realizar outros apontamentos que despertam e/ou fazem alusão, e que também se faz necessário citar, às indicações políticas, econômicas, ambientais e religiosas disseminadas nesta apresentação institucional do Projeto Trem da Vale.

É como se estes aspectos não tão evidentes no filme, por exemplo, estabelecessem uma espécie de trilha temática de sentidos e significados que os idealizadores do projeto buscavam para criar um elo sentimental com os espectadores, focando, obviamente, em seu público-alvo: cidadãos das cidades de Mariana, Ouro Preto e distritos.

Aparentemente o trem não é apenas um Programa de Educação Patrimonial, mas um meio para a Vale se promover, para sinalizar a contribuição da mesma para a região, que é diretamente afetada pelas suas atividades, haja vista o desastre ocorrido na região em 05 de novembro de 2015.

No documentário, nota-se que a promoção do programa e de suas vantagens é mais presente do que aspectos históricos sobre o trem ou sobre os objetivos de um projeto voltado para a Educação Patrimonial, que consiste em desenvolver ações educativas que visem à preservação do patrimônio, da cultura e das tradições, sejam elas materiais ou imateriais, de determinada comunidade, a fim de preservar a identidade local e, principalmente, formar sujeitos críticos, autônomos e reflexivos que sejam capazes de reconhecer e compreender suas origens e a organização social e cultural na qual estão inseridos.

O Trem da Vale apresenta-se como uma caricatura; é o que a empresa quer falar sobre ele. Percebe-se o trem como um apêndice do programa, uma vez que no documentário praticamente não é mencionado a real história da malha ferroviária da qual este trecho faz parte, que a viagem do trem em si tem cunho turístico e não de passageiros.

Já na análise de cada depoimento do livro, identificou-se a presença de esquematismos, que implícita ou explicitamente, são elucidados nos relatos analisados, são eles: padronização; pseudo-individuação; glamourização; aproximação; personalização; hibridização e estereotipagem.

Já de início, o nome: "Programa de Educação Patrimonial Trem da Vale", apresenta-se como uma forma de fetichizar a proposta do trem, dado que as ações desenvolvidas no programa estão mais direcionadas para a preservação - de memórias e espaços - do que para formar agentes críticos, ao restringir o processo de Educação Patrimonial aos objetivos que se enquadram em sua "definição" de Educação Patrimonial. 
Acredita-se que, ao se trabalhar com esta metodologia de forma restrita, perde-se a oportunidade de formar indivíduos com capacidade crítica, enquanto cidadãos atuantes na comunidade. Assim, as pessoas não tomam consciência, por exemplo, de como a Vale se apropria e explora seus bens, sejam eles ambientais ou patrimoniais, como a figura da maria-fumaça, que foi reduzida e caricaturizada apenas como o Trem da Vale, deixando de lado (ou omitindo-se) para as pessoas que desconhecem a história do transporte feito por ela décadas atrás, o valor histórico deste bem.

$\mathrm{O}$ projeto tem estrutura, ou objetivo de uma educação patrimonial, mas não há indícios de que é para educar criticamente o cidadão. Assim, estudos críticos como este não visam menosprezar, e tão pouco, não reconhecer a importância e o valor de um projeto como este, em uma região carente de projetos que inspirem o reconhecimento do bem patrimonial (material $e$ imaterial) como sendo propriedade de cada indivíduo, e não apenas responsabilidade de órgãos governamentais como o IPHAN.

Neste sentido, reflexões sobre a forma como se configurou o Projeto de Educação Patrimonial Trem da Vale se fazem necessárias. Apresentado como um apêndice do programa, o Trem da Vale acaba por se tornar protagonista, um produto fim que contribui para alavancar a imagem da empresa. Um sinal de que a Educação Patrimonial ficou em segundo plano é o fato de que, no momento de crise, a empresa encerrou o Programa de Educação Patrimonial e manteve apenas o passeio turístico. $\mathrm{O}$ arcabouço cultural nada mais é que um caminho para vender uma imagem e/ou um produto.

Através dessas análises preliminares, expõe-se que a comunidade inserida no programa de Educação Patrimonial, não recebeu estímulos suficientes para despertar a consciência de um cidadão crítico, que está além de um cidadão comum que apenas figura na comunidade. Esse cidadão questiona as relações sociais e a sociedade em que vive, observando o seu dever de conhecer, valorizar, preservar e difundir o bem e a memória cultural.

É preciso apreender a concepção de que uma Educação Patrimonial deteriorada contribui efetivamente para a disseminação da herança da Indústria Cultural, tornandose apenas mais uma vertente para fortalecêla $e$ inseri-la em outros ramos culturais $e$, não somente, em áreas ligadas ao rádio/música e à televisão, conforme exposto inicialmente pelos teóricos Adorno $e$ Horkheimer. Assim, espera-se incentivar novos estudos e reflexões na área acadêmica sobre a presença - implícita ou não- da Indústria Cultural no dia-a-dia da sociedade.

\section{Referências}

AdoRno, Theodor; HoRKHEIMER, M. $A$ Dialética do Esclarecimento. Rio de Janeiro: Jorge Zahar, 1985.

CÉsar, P. A. B.; Dhein, C. E.; Uez, P. C. "Paisagem: a dimensão espacial na educação patrimonial". Book of proceedings, v. 1 - international conference on tourism \& management studies - algarve, 2011.

Costa, M. L. P. "Capacitação de Educadores em Educação Ambiental e Educação Patrimonial Focada em Recursos Hídricos: A Fazenda-Escola Fundamar (Paraguaçu/MG, baixo curso do rio Sapucaí)". 2011. 234 f. Dissertação (Mestrado Interdisciplinar em Ambiente Construído e Patrimônio Sustentável). Universidade Federal de Minas Gerais - UFMG, Belo Horizonte. 2011.

Documentário Projeto Trem da Vale. Direção Éder Santos. Coordenação de Produção: Marcelo Braga. Roteiro: Éder Santos, Carol Nogueira e Marcus 
Nascimento. [S.I.]: Emvideo, 2006. 1 DVD (10'53 min.), son, color.

DuARTE, Rodrigo. Teoria Crítica da Indústria Cultural. Belo Horizonte: Editora UFMG, 2003.

FlorêNCIO, S. R.; Clerot, P.; BezerRA, J.; RAMASSOTE, R. "Educação Patrimonial: Histórico, conceitos e processos". Brasília, DF: IPHAN, 2014. 65p. Disponível em: $<$ http://portal.iphan.gov.br/uploads/publicac ao/EduPat_EducacaoPatrimonial_m.pdf $>$ Acesso em 20/04/2016.

Fundação VAlE. Outras memórias, outros patrimônios: relato técnico do Programa de Educação Patrimonial Trem da Vale. Belo Horizonte: Fundação Vale. Rona, 2010.

GRUNBERG, Evelina. "Educação Patrimonial: utilização dos bens culturais como recursos educacionais". Cadernos do CEOM. Unoesc, Chapecó, ano 14, n.12, p.159-180, jun. 2000.

MAltêz, C. R.; Sobrinho, C. P. A.; BITTENCOURT, D. L. A.; MiRANDA, K. R.; MARTins, L. N. "Educação e Patrimônio: O papel da Escola na preservação e valorização do $\mathrm{Pa}$ trimônio Cultural". Pedagogia em ação, v.2, n.2, p.39-49, nov. 2010.

RÜDIGER, Francisco. Theodor Adorno e a Crítica à Indústria Cultural: comunicação e teoria crítica da sociedade. $3^{\mathrm{a}} \mathrm{Ed}$. Porto Alegre: EDIPUCRS, 2004.

Recebido em: 09/03/2018

Aprovado em: 10/04/2018 